\title{
Speaking of clans: language in Awyu-Ndumut communities of Indonesian West Papua
}

LOURENS DE VRIES

Abstract

The place of language in Awyu-Ndumut speech communities of the Indonesian province of West Papua is investigated from the point of view of the parallel but interconnected worlds of clan lands and nation-state sponsored settlements, with institutions such as schools and churches. First, language and identity, language names, multilingualism, linguistic ideologies and special speech registers are discussed from the perspective of clan-based cultural and linguistic practices. Second, the relationship between Papuan languages and Indonesian is investigated from the perspective of the dynamics of the clan land/settlement opposition. Indonesian is talked about by Awyu-Ndumut speakers both positively and negatively. Positively, they speak of it as an interethnic lingua franca. Negatively, they speak of it as the language of "demons", that is people outside the boundaries of Awyu-Ndumut social personhood.

Keywords: Papuan; Indonesian; Awyu-Ndumut; attitudes; domains.

\section{Introduction}

Awyu-Ndumut speech communities of West Papua's Digul River basin provide a fascinating window on key aspects of the relationship between language and society in the linguistic area of New Guinea. ${ }^{1}$ Clan based cultural and linguistic practices, associated with clan lands in the jungle, co-exist and interact with linguistic and cultural practices of recent settlements (Indonesian kampung 'village'). Dutch and later Indonesian rulers of West Papua initiated (or encouraged) such settlements and tried to relocate people from their clan lands to these settlements. Missionaries usually supported, and often also initiated, such processes of settlement formation. Institutions such as schools, clinics, churches, shops or government offices can be found in these settlements. People of different clans, and often also of different languages, live together in 
these settlements. But most of the time Awyu-Ndumut speakers do not live in the kampung but on their clan lands. This is especially true for North Korowai and North Kombai clans who live almost all the time in their high tree houses on the ancestral lands.

Clans and clan-based land rights are not just a factor of the pre-colonial past, they are still essential for survival since most Awyu-Ndumut speakers depend for their food and many other things on their clan lands. But the clan and clan lands are also emotionally crucial as they give people a very strong sense of place, origin and continuity. The picture in much of interior New Guinea, certainly in the Awyu-Ndumut area, is one of parallel but interconnected worlds of clan lands and settlements.

The Papuan languages of the Awyu-Ndumut family are spoken in southwest New Guinea, on the Indonesian half of the island, from the upper part of the 525 kilometer long Digul River to its estuary in the Arafura sea, but also between the Digul and the Mapi River, and from the border area near the Fly River east of Digul all the way to the south-west of the Wildeman River. This vast expanse of lowland covered with swamps and rainforests is the home of around 35,000 speakers of Awyu-Ndumut languages.

For this study, the following languages are classified as Awyu-Ndumut languages: Kaeti, North-Wambon, South-Wambon, Axu, Syiaxa, Pisa, Korowai, Sawuy, Kombai. Not all of this is based on reconstructive work (Healy 1970, Voorhoeve 2001, 2005), but the precise classification of these languages is irrelevant to the overall argument of this article.

In the early 1980s, when I started my linguistic research in the area, AwyuNdumut speakers in north-west lived permanently on their clan lands and foreigners had not yet begun to establish settlements close to their lands, but in the periphery of their world, small, embryonic and unstable settlements had started to form around mission stations with air strips. In other parts of the Awyu-Ndumut lands, to the south and east, processes of integration in nation-states had commenced decades earlier, for example Kombai clans living close to the Digul River had seen Dutch efforts to relocate them from clan lands to settlements in the 1950s. The process of moving from their traditional high tree houses on the clan lands to the low houses in multi-clan villages was not always voluntary. Older Wambon men told me that Dutch patrols in the 1950s sometimes burned down tree houses when people refused to move to the state-initiated settlements. Around the year 2009 most, if not all, Awyu-Ndumut clans lived in the parallel worlds of settlements and clan territories.

First, I will describe language as it functions in Awyu-Ndumut clan worlds, based on both linguistic (de Vries and Wiersma 1992; van Enk and de Vries 1997; de Vries 1993, 1995, 2005, 2006, 2010) and anthropological research (Stasch 2001, 2007, 2008, 2009). 
The first section starts with a discussion of clans as fundamental to AwyuNdumut society, especially in relation to land, and then looks at the following topics from this clan perspective: language and identity, language names, linguistic ideology, lexical substitution registers and "secret" parts of the vocabulary, multilingualism and borrowing. In the second part, the perspective shifts from clan worlds in the jungle to the settlements and to the interaction between the worlds of settlements and clan lands. There the relationship between Indonesian and Awyu-Ndumut languages is the central theme.

\section{Language in Awyu-Ndumut clan worlds}

\subsection{Clans}

Speakers of Awyu-Ndumut languages conceptualize society primarily in terms of named patriclans, each with its own clan land. Clans tend to be small, with rarely more than 80 people, and it is not uncommon to find clans with less than 15 people. Some have died out. Land and territoriality form the heart of clan based conceptualizations of social life (Boelaars [1970: 16] for Mandobo; Stasch [2009: 26-36] for Korowai). Prolonged co-residence on clan land "tends to make people owners, and co-residence tends to make people clan mates, [and] as non-agnates over time become identified with a homeland, grow comfortable residing there" (Stasch 2001: 308). The clan lands are so essential that:

Landownership tightly joins three categories: "place", "clan," and "owner". A place bolüp ... is usually a contiguous, irregularly shaped segment of land, typically about a square mile in expanse. A place is by definition the territory of a particular named clan, and all clans have places. Korowai ubiquitously speak of different parts of the landscape by combining clan names with the term bolüp. For example, dambol-bolüp is 'place of Dambol'. (Stasch 2009: 28)

Although clans have a central role in relation to landownership, give people a place in life, and are the highest political units, Stasch (2009: 9) emphasizes that they should not be thought of as closed, tight-knit face-to-face communities that do and decide all sorts of things as clans. In fact, apart from (pig or sago grub) feasts that require the efforts of the whole clan and that are organized at clan level, life on the clan lands is lived mostly in smaller family groups, for example a man with his wives and their children in their tree house or two brothers with their wives and children. Major decisions are not taken on the level of the clan but rather on the level of the family, or the individual, man or woman. Marriage choice, for example, is not a clan decision, mostly based 
on individual choices and attraction between individuals, within norms of clan exogamy and genealogical distance (Stasch 2009: 173-207). Individual autonomy in all domains is highly valued in Awyu-Ndumut communities.

The overall picture is one of dispersion (Boelaars 1970: 64; Stasch 2009: 25). Dispersed over the Awyu-Ndumut lands we find thousands of small clans that in turn consist of families and individuals living scattered over the clan land. The strong tendency toward political autonomy and egalitarianism favors dispersion. Residential mobility at the individual and family level is very high. People move often for shorter or longer periods to their mother's brother's clan lands, couples may live for a while with clan people of the wife. Families move regularly from one tree house to another on the clan land. Stasch (2001: 70) writes of the Korowai "this situation of extreme residential mobility and residential dispersion is one of the most striking aspects of Korowai social life". The composition of a household in a tree house accordingly is highly variable and changes all the time.

Clan membership divides people into categories of people (Stasch 2009: 34). The Korowai noun for patriclan gun is also used to denote species of plants or animals and "people do readily compare the diversity of animal and plant species to the diversity of names of human clans" (Stasch 2001: 303). Clans tend to have animals or plants as mythic founding fathers. Speaking the names of these plants or animals are taboo in the presence of members of clans with these plants or animals as forefathers (van Enk and de Vries 1997). Clan members will not eat the plants or animals considered to be founding fathers.

A woman normally moves to the clan lands of her husband and will be buried there, but her links with her father's and brothers' clan remain strong. The children of the woman have close ties to their mother's people, especially boys to their mother's brothers, a link institutionalized in the avunculate, the dyadic relation of mother's brother and sister's son, found in many variations in New Guinea, usually in the context of Omaha-type kinship systems (e.g. Manambu, Aikhenvald [2008: 17]). Boys will often stay with their mother's brothers, demand indemnity payments upon such uncles' deaths, protect their uncles (and they in turn protect their sisters' sons) in case of accusations of witchcraft and other conflicts.

These uncles often help find a bride for their sisters' sons among their own classificatory daughters or among the women of their uncles' clans (grandparental clan brides: many Korowai men marry a woman they call max whose common referent includes 'grandmother' in their Omaha-type kinship patterns, still using this term after marriage).

The picture of Korowai clan communities drawn by Stasch $(2001,2009)$ is representative of what I saw in Kombai and Wambon areas and patterns of clan life observed by Boelaars (1970) in the Mandobo area. I do not claim that 
all Awyu-Ndumut groups have the same culture or even the same notions of "clan", but only that they share a number of cultural practices with far reaching linguistic implications. The most important of these shared elements is the extreme political fragmentation into very many and very small exogamous units, called "clans" for the purposes of this article, that regulate communal and inalienable ancestral land ownership. (These clans have no form of social or political integration higher than units clans.) Exogamy across linguistic and cultural borders, the avunculate, the love of individual freedom, egalitarianism and autonomy of clans, dispersion, and residential mobility are other shared elements of Awyu-Ndumut clans. Again, these elements occur all over New Guinea in various permutations and configurations but it seems that in the coastal plains, both north and south of the central mountain range, social, political and linguistic fragmentation is most intense.

\subsection{Clans, language and identity}

Clan membership is the most central element in a person's identity. Clan names dominate everyday talk of Awyu-Ndumut people because the default way to refer to people is "the X person" where X is a clan name (Stasch 2001: 304). When asking someone who he or she is, the answer will contain a clan name. The clan lands are perhaps the most focal element in the clan notion. They are literally and figuratively your place in life (e.g. Kombai mbürü means both 'place' and 'clan territory'). Language transcends clan lands; people of many different clan lands may share a language. But among the Awyu-Ndumut, language as a clan transcending entity is never the focus of identity construction. Not language but clan affiliations determine who you are. First of all, your father's clan; through your father you share in the communal ownership of a home land, the land that feeds you and gives you a place where you belong. But you are also a child of your mother and she comes from another clan, the clan of your mother's brothers. The important institution of the avunculate ensures that the link with mother's people strongly co-determines who you are. And then there are the grandparental clans and the clans of your wives. This network of clan links, with the father's clan in the centre, provides identity, tells you who you are and where you belong. The father's clan is by far the most important in identity construction, especially for men who stay on their ancestral lands after marriage, because of the all-important issue of land and land rights. However, other clan links, first of all the mother's brother's clan, must be mentioned because of the relational nature of identity construction in Melanesian contexts, persons as clusters or bundles of relationships (see below, sociocentric or relational notions of identity). A person is not only a son but also a husband and a cross-cousin and this brings the other clans 
into the identity equation. These different dyads imply numerous rights and obligations.

People of unrelated clans are "the others", even if they speak just like you. And people that speak a (very) different language may be your own people in the Awyu-Ndumut world where your mother's people often speak a different language or a different dialect. This happens because with so many languages, spoken by very small numbers of people (around 1500 per Awyu-Ndumut language), exogamous clans will often receive brides with a (very) different language. These women tend to take the language of their original clan with them to the clan territory of their husbands and many Awyu-Ndumut children grow up with mother's and father's language.

This does not mean that women do not adopt and use the language or dialect of their husband's clan. But in a bilateral clan world, it is vital for a child to establish and maintain links with father's people and mother's people and normally a woman will pass on at least some of her language. Children are keen to learn the language of their mother's brothers because they play a key role in their life and they will often spend a lot of time on their maternal uncles' clan lands, and there they adjust their language as much as possible to the language of their maternal relatives. Everywhere in the Awyu-Ndumut area I met people who had grown up with two or three languages or dialects, for example Korowai-Kombai-local Malay and Korowai-Citak-local Malay speakers in Yaniruma. The sociolinguistic survey of Susanto (2004: 16) observes: "People in Boma II understand Kombai, also, since there is a lot of intermarriage in this village between Jair and Kombai." In the border areas with Asmat, Ok and Marind languages, Awyu-Ndumut speakers frequently marry speakers of those other language families.

Although language as a clan transcending entity therefore has a modest place in the construction of identity, there are at least two ways in which language does play a role in identity construction in Awyu-Ndumut communities. It happens in parts of the lexicon that are linked to origin of clans and of individuals. And second, it happens in the framework of sociocentric linguistic constructions of personhood (Foley 1997: 266).

First, I will discuss some examples of words and names in the lexicon that are linked to origin and identity of clans and of individuals. Awyu-Ndumut clans commonly have oral traditions that describe a plant or animal as the mythical totemic ancestor and founding father of the clan. It is taboo to eat totemic plants or animals. For example, the origin story of the Korowaispeaking Khomei clan, published by van Enk and de Vries (1997: 170-173), tells how their ancestor, a lizard, determined where his offspring should live and how some of the offspring of the lizard became Kombai and others Citakspeaking clans. Citak is a neighbor of Korowai but of a different language family, Asmat-Kamoro. The totemic clan names are called khondum $f i$ 'hidden 
names' by the Korowai (Stasch 2001: 310). Hidden names can only be known to and uttered by adult men of clans who own the origin stories and who tell them only during the night, on special occasions and never in the presence of outsiders. Origin, identity, and power are closely linked: to know the origin of something or someone is to know the identity and true nature of that person or thing. To know the names of original beings or persons gives power because in uttering those names true identities are exposed and possibly damaged or destroyed in certain contexts.

Among Korowai, personal names given to babies are likewise based on notions of origin and true identity embedded in reincarnation beliefs (van Enk and de Vries 1997: 40-41). Every baby is born as a reincarnation of a dead relative and a spirit medium determines the names to be avoided in the presence of the child. Besides calling these avoided terms the person's khokhulop, Korowai also call a reincarnation identity the person's 'hidden name' (khondumfi), to be avoided (lakhap) in his or her hearing. Implicit in these reincarnation beliefs of origin and identity is the notion of clan. Clan membership does not stop at death. There is a kind of parallel world of clans in the land of the dead. These dead ancestors decide who among them will return to the clan land of the living by entering the body of a baby just before birth (van Enk and de Vries 1997: 41). What enters that body is the yanop-khayan 'true person' or 'soul' of the dead ancestor

Not surprisingly, in myths of origin of Awyu-Ndumut speakers we encounter many 'hidden names'. For example, Drabbe (1959: 10) observes that Mandobo origin myths contain two kinds of names, names that may be known by everyone and names that are ketpon 'taboo/secret'. Women and children are not allowed to know these 'hidden names' and therefore are excluded from listening to these origin stories. For example, the ketpon name of the Papuan hornbill Aceros plicatus (Indonesian burung tahun), is Tüot-Kejenip (Drabbe 1959: 70). These 'hidden names', the part of vocabulary linked to clan origins, clan identities and oral traditions of the clan, reflect and express clan identity in language.

The second way in which language plays a role in expressing identity is related to sociocentric or relational concepts of personhood, the person as a cluster of dyadic relations. Both the person and the clan are perceived as clusters of relationships and each relationship contributes to who you are, is an element of your personal or clan identity. Foley (1997: 266) speaks in this context of a sociocentric construction of identity. These relationships are defined in terms of rights and obligations within dyadic relationships such as mother's brother and sister's son, brother and sister, husband and wife, male ego and wife's mother. Ceremonial exchange of wealth items, compensation/ indemnity payments and other ritual forms of exchange are used to express and maintain these dyadic relationships. 
New Guinean conceptualizations of personhood are radically different: a partitive amalgamation of various substances from the different exchange interactions that one is ultimately built up from. From such a vantage point, the understanding of a speaker, the articulation of personhood through language is also radically different. This has fundamental implications for how New Guineans think about language and questions of language varieties and language purism (the latter notion in fact unintelligible in such a scheme). (Foley 2005: 163)

When two clans or two individuals with different languages or dialects have a relationship in the context of trade, marriage, or otherwise, the partners not only exchange goods to symbolise their relationship but they also exchange also elements of language. By borrowing elements from the language of partners and relations, these sociocentric conceptions of identity are expressed in language. For example, by learning the language of its mother's people, in addition to the language of its father's people, a child expresses its bilateral identity that is linked with father's and mother's clan. In other words, not only a person or a clan but also language itself is "a partitive amalgamation of various substances from the different exchange interactions" (Foley 2005: 163).

\subsection{Clans, language names and linguistic ideologies}

The two parallel worlds of the clan lands in the jungle and the kampong settlements, with their nation-state related institutions, are reflected in the language names for Awyu-Ndumut languages. There are two types of names for them, names that reflect the settlement perspective and names that reflect the clan perspective. But language names are just a part of a much wider field of metalanguage, of how language is talked and thought about. The metalanguage of clan people and of the foreigners that interacted with them was very different because they have very different linguistic ideologies.

The names of Awyu-Ndumut languages as found in linguistic publications (Korowai, Kombai, Aghu, etc.) are all exonyms, names that reflect the settlement perspective, names given by missionaries, government people, or linguists for arbitrary sections of Awyu-Ndumut dialect chains that happened to be spoken around government or mission posts that formed the core of major settlements. There were of course no indigenous names for these languages. Awyu-Ndumut speakers themselves talked about the languages they spoke with expressions such as "people's language", "our language", "language of clan such and such", "how we people speak". Awyu-Ndumut speakers designated themselves consistently as "persons" or "people" (see Section 3.2 for the meaning of these "person" terms in relation to boundaries of social personhood), in some contexts qualified by clan names ("we are Weremba people") 
or expressions such as "that belong to this place" ("we are people that belong to this place/clan land".) When clan people identify themselves, they never do so in terms of language but in terms of the clan lands where they belong.

Exonyms such as Korowai and Kombai therefore did not denote linguistic entities recognised or named by Awyu-Ndumut clans, they were purely constructs of outsiders and the terms Awyu-Ndumut speakers used for their own language did not refer to the same entities as the terms of the outsiders. For example, the normal Korowai self-designation is bolü-anop 'place/clan territory person' (Stasch 2009: 41), that is 'people that belong to this place/clan land'. "The terms bolü-aup 'homeland language' and bolü-an-aup 'homelandLOC-language' are Korowai speakers' main nominations for their own language ... being somewhat more frequent than kolufo-aup" (Stasch 2001: 60). The latter name kolufo-aup is in fact an exonym that means "upstream language' (Stasch 2009: 43) and is an example of a stream-based name given by outsiders who Indonesianized the term kolufo 'upstream' into the exonym Korowai.

The nouns glossed as "language" should be understood against the background of local perceptions and concepts of "language" as action and as sound. For example, the noun $l u$ in the Kombai expression khombaye-lu 'person's speech' may mean 'voice', 'word', 'promise', 'message', 'question', 'utterance'. It refers to actions performed through speaking. Khombaye lu as selfdesignation basically means '(how we) people sound'; just as different kinds of birds produce different calls $(l u)$, people of different places sound differently. When other people have a different pronunciation, even with mutual intelligibility, they have a different $l u$ 'speech'.

Many of these "person/people" based self-designations, not understood and mispronounced by outsiders, were in Indonesianized forms taken to be names for the "languages" or "ethnolinguistic groups" that outsiders constructed for parts of dialect chains spoken around newly established settlements. That is why several Awyu-Ndumut language names can be traced back to expressions that mean 'people' or 'person' or to names of clans. For example, the language name Kombai is based on an Indonesian version of the expression khombaye lu 'people's speech' (de Vries 1993: 1). The language name Kaeti stems from the ethnic self-designation küap kaeti 'true/real person' (Drabbe 1959: 4). The language name Aghu comes from aghu 'person' (Drabbe 1957: 1).

Since cultural geography is stream-based, sometimes names of rivers or streams or terms like 'upstreamers' (e.g. kolufo 'upstream', Indonesianized as Korowai, Stasch [2009: 43]) became exonyms for Awyu-Ndumut dialects spoken along those rivers. Kaeti (or Mandobo) is also known as Ndumut, the name of a river along which they live. Mandobo speakers told Boelaars that government people who started the Tanahmerah post called them Mandobo, an exonym that might be a combination of Mandup and Wambon (Boelaars 
1970: 27), terms Mandobo speakers use for people on the right and left banks of the Kao River. Sjiagha and Jenimu are stream-based names (Drabbe 1950: 93) given by the linguist Father Drabbe to the dialect of clans living close to those streams.

Missionaries, linguists, and government people often had linguistic ideologies that originated in nation-states with national languages, ideologies that correlate languages, cultures, and political entities in a kind of unholy trinity. They tended to construe both language and cultures as homogeneous, bounded entities with language as expressing culture and as strongly linked to identity. For example, they assumed that the languages (which they themselves had constructed as linguistic units) such as Mandobo or Kombai, expressed Mandobo and Kombai "cultures". However, there were no Mandobo or Kombai cultures. Clans that speak the same language often have different cultural practices based on different histories of contact, marriage and trade with other clans, across linguistic and cultural borders.

Linguistic and cultural homogeneity and the idea of bound, discrete entities called "Kombai language" or "Korowai culture" is the very opposite of the linguistic and cultural realities of New Guinea clan communities, where people may have a mother tongue and a father tongue, where speakers' identities are not threatened by multilingualism, borrowing, mixing and adjusting linguistic and cultural practices to cross-language partners in communication, but rather the opposite, since relationally conceived identities are expressed by multilingualism, borrowing, and mixing.

Nation-state agents expressed their linguistic ideologies in the organization of the settlements and in the local administrative system. The multilingual settlements were divided into sections, each section with its own "language" and its own headmen. Awyu-Ndumut people living in those settlements adopted the terms such as suku Korowai 'Kombai tribe' and bahasa Kombai 'the Kombai language' that the foreigners had introduced to talk about them and to organize the settlements. In kampung contexts, Awyu-Ndumut speakers learned to talk and think about themselves in Indonesian as orang Kombai 'Kombai people' or orang Mandobo 'Mandobo people'.

Language functions indeed very differently in clan worlds than it does in nation-states with unifying and standardized national languages. Accordingly different linguistic ideologies emerged in Awyu-Ndumut clan worlds. Foley (2005: 157) defines linguistic ideology as "that cluster of beliefs that a particular speech community holds about the form and function of language". These ideological beliefs do not form theories of language per se "but rather the background of largely unexamined assumptions that guide the construction of specific theories, be they folk theories or scientific ones" (Foley 2005: 157).

Linguists and missionaries tended to do their research in the settlements rather than on clan territories and they viewed linguistic reality from that kam- 
pung perspective rather than looking at linguistic and cultural reality from a clan perspective. One of the exceptions was Heeschen (1998: 24) who observes in his description of the Eipo language of the eastern highlands of Indonesian Papua: "When it is stated: the Eipo language has the rule $\mathrm{x}$, the reader should bear in mind what has been stated here about the smallness of the speech community and its norms. The rule should properly read: the speaker $y$ or the group of men from such or such a clan ... say ' $x$ ' under certain circumstances."

In clan contexts of Awyu-Ndumut speakers linguistic, cultural and political units are not perceived as correlated. They cannot be perceived as correlated in clan societies where languages transcend the boundaries of the clan, and speakers of the same language live on a different clan territory and may be your enemies. Perhaps the sharpest difference in the linguistic ideologies of Awyu-Ndumut clans and the representatives of nation-states who studied their languages resides in the conceptual network of clan notions of origin, identity, iconicity, spiritual power and secret knowledge. From that perspective, language is not just an instrument to refer to things, and words are not arbitrary labels for things. Rather, in certain contexts, words are perceived as elements intrinsically, causally and iconically linked with the origin, essence and hidden nature of things (Stasch 2008: 9-11), and with the spiritual power and presence of the things or persons named. That is why pronouncing words in certain contexts is a dangerous and undesired act because it may have all sorts of consequences, such as evoking the presence and power of persons or things; diminishing the spiritual power of these things and persons; weakening the clan; diseases; earthquakes and other disruptions of the natural order. That is also why avoiding certain words is part and parcel of everyday language use, a constant and central part of linguistic behaviour. This leads to lexical substitution registers, institutionalized links between word pairs in the lexicons of clan languages.

Lexical substitution registers with various forms and functions occur all over New Guinea (and Australia). Registers of vocabulary substitutions may have poetic functions, artistic functions, ritual functions, function in kinship contexts or may have pragmatic functions of indirection, humor, persuasion or function to express anger and frustration (Stasch 2008: 7). These registers often reveal key aspects of linguistic ideologies of New Guinea clans.

The Korowai khokhulop register described by Stasch (2008) exemplifies some of these aspects of linguistic ideologies emerging in Awyu-Ndumut clan contexts. Stasch compares the Korowai khokhulop lexical substitution register with the substitution practices of the neighboring Asmat (Stasch 2008: 7). According to Stasch (2008: 8), khokhulop is a compound noun consisting of khokhu 'root, origin, cause, meaning' and -lop 'location, site' which means something like 'underlying identity'. Both the Asmat and Korowai substitutive 
Table 1. Korowai words with their khokhulop substitutions

\begin{tabular}{ll}
\hline Normal designation & Khokhulop substitution \\
\hline nan 'rattan' & yanop-khul 'human intestine' \\
dul 'penis' & wafol 'earthworm' \\
laun 'pandanus sauce' & khi-ol-akh 'dysentery' \\
melil 'fire' & bun-kha 'blood' \\
\hline
\end{tabular}

pairings are based on iconicity (Stasch 2008: 10): Asmat and Korowai speakers perceive resemblances between the paired items. Certain pairs, e.g. 'moon' as the substitute for 'sun' and certain marsupial species names for dogs, are shared by Korowai and Asmat.

Korowai speakers often talk about the khokhulop register of which they have a high metalinguistic awareness and say things like 'A, its khokhulop is B', with examples of khokhulop substitutions in Table 1 (Stasch 2008: 6, 10-13).

According to Stasch (2008: 16) the force of these pairings goes beyond metaphorical correspondence or iconic resemblance and is ultimately based "on ontological, causal closeness that is felt to be behind [it] that manifests iconic similarity. Vines originally were snakes and saying 'snake' around vines causes them to break". Stasch (2008: 6) writes: "Speech is not only about the phenomenal world but of it. Language is analogous to touch and other sensory channels, and analogous to forms of interaction in those physical channels such as bodily harm."

Persons also have khokhulop names and "personal khokhulop correspondences underscore the force of sound alone. ... An individual does not need to know his or her khokhulop in order to be damaged by hearing it uttered... . Even accidental utterance of a homonym or near-homonym of a person's hidden name is enough" (Stasch 2008: 20). This leads to elaborate linguistic avoidance behaviour as people constantly try to talk around khokhulop nouns.

\section{Language of demons and humans}

\subsection{Domains of Indonesian and Awyu-Ndumut languages}

In the process of settlement formation, speakers of Awyu-Ndumut languages came into contact with local varieties of Indonesian, mostly Papuan Malay.

Both the Catholic missionaries and the Protestant missionaries of the mission of the Dutch Reformed Churches (ZGK) used local Papuan Malay varieties of Indonesian in their school, health and church activities, under 
both Dutch and Indonesian rule. Missionaries tended to be the first foreigners that settled in Awyu-Ndumut lands; they were followed by government people, usually very few and confined to main stations in the interior, and by petty traders, often Buginese or Makassarese, who opened shops in the main stations.

All these foreign people and institutions are associated with kampung settlements, not with clan lands. Most foreigners had very predictable patterns of movement and location; they would travel either by boat or by plane, from one kampung to another. They hardly ever travelled overland to the clan territories of Awyu-Ndumut people to interact there with them. Rather, Awyu-Ndumut people were invited or pressed to come to the newly established kampungs, usually consisting of an airstrip or a small harbor suitable to motorized boats, with a church, sometimes a clinic, a school or a government building, and one or two rows of kampung houses for locals. The language of the institutions found in kampungs was Indonesian, also used in the shops, in most churches, in the school and in the clinic.

In practice, since people have no means to subsist in the kampungs, dependent as they are for food and building materials on the clan lands, most of the time the kampungs are deserted or semi-deserted, with a handful of people who need to be in the kampung for various reasons, for example to get medical treatment, to go to schools or to visit the church or shops. But since the teachers, health care workers and other foreigners often leave their posts in the interior to go the coastal cities, for example to receive their salaries, many kampung are ghost towns much of the year.

The fact that foreigners normally stayed in kampungs and expected people to come to these kampungs suited local people very well, given their preference to be autonomous individuals on their clan lands, in highly dispersed, loose, egalitarian clan communities. Outsiders settling in kampungs was an advantage to the Awyu-Ndumut because it protected them from unwelcome visitors on their clan lands and led to minimal interference from foreign institutions on the clan lands. This set up a system with two parallel worlds, the world of the kampung and its institutions and the world of the clan lands in the jungle. These worlds are connected and co-evolve in the course of time, and the dynamics of the interaction between these two worlds varies with time and place in Awyu-Ndumut communities.

People are very much aware of the fact that they live in these two worlds, each with its own linguistic and cultural practices. In the late 1980s when I lived in the Kombai kampung of Wanggemalo and the Korowai-Kombai kampung Yaniruma, people had begun to adopt two personal names that they called in Indonesian nama gelap 'dark name' and nama terang 'light name'. The nama terang was their Indonesian name, often taken from the Bible or from objects associated with foreigners, for example a person would be called Petrus 
or Pilot or Maik (after a pilot's name). These names were used exclusively or mostly when they were in the kampung. While on the clan lands, they used indigenous personal names such as Mbürüfare in reference to persons. (This was the Kombai name of one of my language consultants, a name that means 'clan land man'; while in the settlement of Wanggemalo people would refer to him as Petrus; personal names are mostly used in reference, avoided in the presence of the person with that name.)

Interestingly, quite a few would only wear Indonesian style clothing while in the kampung and change into grass skirt/penis gourd while on the clan lands. The dichotomy of kampung versus clan lands was also reflected in other cultural practices, for example witch executions as a rule took place on clan lands, not in kampungs where the Indonesian justice system was supposed to be in force. Similarly, sago grub feasts were always on clan lands, never in the kampung. Church services were never on clan lands, always in kampungs. Sick people would use western medicine while in the settlements and traditional cures and plant medicine while on the clan lands. Most people, including those not interested at all in Christianity, go to church when in the settlements and perform traditional rituals and ancestor-related sacrifices on the clan lands.

The opposition between clan lands and settlements created a clear division of domains for Awyu-Ndumut languages and local Papuan Malay varieties. Papuan Malay is used in kampung contexts as interethnic lingua franca and as language of certain (nation-state linked) institutions and shops, Awyu-Ndumut languages are used both in kampung contexts between Awyu-Ndumut speakers and on clan lands. Interaction in school, shops and government offices in the villages is in varieties of Indonesian, ranging from basilects of Papuan Malay to acrolects that approach standard Indonesian. Church services may be either mostly or exclusively in local Malay varieties or in Awyu-Ndumut languages, with intermediate forms that employ both.

Most Awyu-Ndumut speakers have some command of Papuan Malay. Roughly speaking, age, gender and distance to the coast determine the extent to which people know Papuan Malay. Most interior villages have elementary schools where children learn Indonesian but teachers tend to be away many months a year which reduces the actual teaching time considerably. Men speak Papuan Malay generally better than women, and younger people speak it better than older ones. Since women bring their languages with them to the clans of their husbands and also learn the languages of their husbands, women are "sometimes particularly associated with multilingualism in languages other than Indonesian" (Stasch 2007: 101). Towards the foothills of the central mountain ranges where kampungs opened either very recently (the last decade) or where people still live exclusively on clan lands in tree houses (e.g. some parts of North Korowai), people know very little Papuan Malay, if at all. To 
give an idea of the advance of Indonesian in relation to the start of village formation, the Kombai-Korowai village Yaniruma was begun in 1979, when hardly anyone of the Korowai around the mission station spoke Indonesian. But "as of 2002, about 5 percent of Korowai spoke Indonesian well enough that they would do so regularly in the presence of more than just one person, and the number of Indonesian speakers was growing quickly" (Stasch 2007: 100).

There is one major exception to the rule that varieties of Indonesian are not used on clan lands: during sago grub or pig feasts where hundreds of people from a wide area come together, Papuan Malay may be used as lingua franca when people cannot understand each other. When Awyu-Ndumut people with different languages meet each other while travelling in the jungle, they will also use Papuan Malay. For most Awyu-Ndumut speakers this interethnic lingua franca function is very useful, reflected in how they call Indonesian bahasa umum 'general language' in Indonesia. But the terms they use for Indonesian when speaking Awyu-Ndumut languages make very clear that there are other, much more negatives elements in their attitudes towards Indonesian.

\subsection{Language attitudes}

The analysis that Stasch (2007) presents of Korowai attitudes towards Indonesian is valid for Awyu-Ndumut communities in general: a fundamentally ambivalent attitude that has its roots in ambivalence towards the settlements or kampungs that on the one hand give access to the wider world and on the other hand bring that same world threateningly close to the clan worlds with their autonomy and cherished clan lands.

When Awyu-Ndumut speakers refer to "Indonesian" in Indonesian, they say bahasa uтиm 'general language' and hardly ever the standard term Bahasa Indonesia, 'Indonesian language' (Stasch 2007: 99). The avoidance of the term Bahasa Indonesia, a term many Awyu-Ndumut speakers learned in elementary school, should not be interpreted as a reflection of anti-Indonesian political sentiments (Stasch 2007: 98); rather, the term bahasa umum reflects what Awyu-Ndumut speakers see as its basic function, namely as lingua franca, a means to communicate across linguistic boundaries, including with neighbouring Papuan groups.

Long before Indonesia started to rule over West Papua in 1963, varieties of Indonesian, then called Malay, functioned as lingua franca in New Guinea. The Dutch also used Malay in their communication with the inhabitants of Dutch New Guinea following a practice dating back to pre-colonial times. In the southern parts of Awyu-Ndumut, towards the coast, Awyu-Ndumut speakers 
have been used to Malay as a lingua franca ever since the first Dutch missionaries and government people arrived in the 1920s and 1930s.

For ambitious young men who want to buy the things they see in the shops in the settlements and who want jobs, learning Indonesian, bahasa umum, is a requirement to get access to jobs and money and to the wider world. Young bachelors have a high residential mobility and are overrepresented in the settlements. They have a pragmatic attitude towards the bahasa umum as a tool to improve their life. Given the sociocentric practices of identity expression, discussed above, it is natural for (usually younger and male) Awyu-Ndumut speakers who have valued ties with foreigners in kampung contexts, to reflect these personal relationships in their language use, both by speaking bahasa umum and by mixing in lexical and grammatical elements from Indonesian when speaking Awyu-Ndumut languages, even when they are on their clan lands. By doing so, they signal their valued relationships with these bahasa umum speaking people, relationships that are part of their personal identity, alongside clan and other relationships.

However, Papuan Malay is not only seen as the bahasa umum, a language for interethnic communication, it is also strongly associated with the world of the foreigners in the settlements. From the very beginning, the foreigners at the kampungs, whether missionaries or government officials, explicitly or implicitly, tried to integrate clan people into the wider Indonesian society, with its institutions of school, clinics, churches and government. At the same time, foreigners needed clan lands for airstrips, mission stations, kampungs, and sometimes for economic activities (oil companies, logging).

In other words, the world of the settlements, with all its attractions of shops with desirable things, job opportunities, clinics and schools, is also a threat to the worlds of egalitarian, autonomy-loving, individuals and, most of all, a threat to clans and their land rights. This is the basis for the ambivalent attitude of most Awyu-Ndumut speakers towards Indonesian. It is also why they always use very negative terms for Indonesian in Awyu-Ndumut languages, terms that reflect the aspects of "otherness" (Stasch 2007), of unwelcome intrusion into clan lands and of existential threat to clan life itself. For example, the name for the Indonesian language in Korowai is laleo-aup 'demonlanguage' (van Enk and de Vries 1997: 103) and in Kombai khwaye-lu 'demonlanguage' (de Vries 1993: 2).

To understand why speakers chose this name for the Indonesian language we need to understand notions of social personhood, and especially the (changing) boundaries of Awyu-Ndumut social personhood. When Awyu-Ndumut speakers refer to their own languages they do so (see Section 2.3) with phrases or compounds containing a noun that means 'person' in the sense of 'normal' person, a term reserved for people within the boundaries of social personhood, e.g. Kombai khombaye-lu 'persons' language'. But when they talk about Indo- 
nesian, they always use expressions containing a term reserved for people outside the boundaries of social personhood.

There are two main terms in these languages for people outside the boundaries of social personhood: 'demons' and 'witches'. Following the analysis of Stasch (2001, 2009), the relationship between the terms for 'person', 'demon' and 'witch' can be described as follows. The simplest way to understand the relation between these three notions is to see xaxua 'witch' as the cause of death of yanop 'person' and laleo 'after death demon' as the result of death. All deaths of yanop 'person' are in principle caused by хахиа 'male cannibalistic witches' and all yanop become laleo 'after-death demon' once they are dead. In the words of Stasch (2001: 444): "Thus, Korowai experience of death is dominated not by one monstrous figure but two. Death's outcome is personified in the figure of the laleo 'demon', while death's source is personified in the figure of the хахиа 'witch'.... It is difficult to exaggerate the scale and intensity of people's daily preoccupations with these two monsters."

Let us start with the demon concept, Korowai laleo. We find laleo in at least five contexts: it is applied to 'after death demons' (a ghost-like but corporeal form that yanop turn into after death), to newborn babies, in swear words and oaths, to foreigners, and it occurs in numerous nouns denoting things introduced by foreigners.

The first and most basic meaning of the demon terms is after-death demon or zombie. According to Stasch (2001: 324) "demons are the principal thing humans become after death. People describe these demons with vivid horror, and worry daily about the possibility of these monsters interfering with their lives." The interference element, mentioned by Stasch, is important to notice because foreigners are also seen to interfere a lot by Awyu-Ndumut speakers. The gloss 'demon' is only an approximation that obscures the corporeal but intensely putrid nature of laleo. They have rotting, disfigured, stinking bodies, with flesh sliding down from their bodies, their bodies are decaying corpses (Stasch 2001: 327).

Because laleo are humans changed into something disgusting and repulsive, the term is extended to other categories of beings that are found to be repulsive because of their otherness, such as newborn babies and foreigners, because they look like humans but have so many disgusting properties that they are denied social personhood.

Newborn babies, with the blood of their birth on them, therefore begin their lives as laleo 'demon', with all the associations of disgusting otherness of 'demons', rather than yanop 'person'. They can be gradually and ritually turned into yanop in the course of the first weeks and months of their lives, that is, if the mother decides to keep the newborn baby.

The (repulsive) otherness of foreigners, both physically and culturally (such as their strange smells, pale skins, weird habits), the fact that they intrude on 
Table 2. Noun compounds formed with the word for 'demon'

\begin{tabular}{|c|c|c|c|}
\hline \multicolumn{4}{|c|}{ Kombai } \\
\hline doü & ‘sago’ & khwai-doü & 'rice' (demon-sago) \\
\hline riya & 'torch' & khwai-riya & 'flash light' (demon-torch) \\
\hline$l u$ & 'sound, voice, language' & khwai-lu & 'Indonesian' (demon-language) \\
\hline \multicolumn{4}{|c|}{ Korowai } \\
\hline aup & 'word, language' & laléo-aup & 'Indonesian language' (demon-language) \\
\hline ndaü & 'sago' & laléo-ndaü & 'bread' (demon-sago) \\
\hline khal & 'skin' & laléo-khal & 'clothing' (demon-skin) \\
\hline
\end{tabular}

clan territories and claim clan land for airstrips and settlements - all these things contribute to the idea that foreigners are not yanop '(normal) person'. Foreigners are not within the boundaries of social personhood and this makes the metaphorical extension of the term khwai (Kombai) or laleo (Korowai) to foreigners understandable.

The skin is important culturally to Awyu-Ndumut people, in many contexts and also in relation to the 'demon' concept. In the early 1980s Korowai and Kombai people would often inspect my skin, feel it and conclude from its paleness and ugliness that I was indeed a 'demon' and that my skin was the skin of a dead person (as my Kombai friend Geyo Weremba later told me, somewhat embarrassed).

Very many of the unknown and strange objects associated with the foreigners entered the lexicon of these languages through an extremely productive formation of noun compounds with the demon term as modifying noun, as in Table 2.

The very productivity of this process mitigated the negative aspect of the demon terms since many of the things denoted by demon compounds are highly desirable and not repulsive at all, such as flash lights and matches. Among younger speakers, those who live in kampungs and have gone to school and with aspirations to move to cities such as Merauke or Jayapura, the demon terms laleo and khwai have lost much of their original negative force when applied to foreigners, meaning probably just 'foreigner' (Stasch 2007: 105). Stasch (2007: 105) even observes that some speakers experiment with compounds such as amerika-anop 'Americans', Indonesia-anop 'Indonesians', tulis-anop 'tourists' to talk about categories of foreigners. This is significant because the noun (y)anop 'person' implies social personhood, something previously denied to foreigners. However, as Stasch (2007: 105) points out, "it is important to acknowledge the severe intellectual and emotional shocks that the Korowai have experienced in their involvement with the new foreigners. Some Korowai who have not interacted much with foreigners con- 
tinue to posit a relation of literal identity between foreigners and the demonic dead."

Stasch (2007: 105) is also correct in pointing out that whereas elsewhere in New Guinea (white) foreigners have been assimilated to dead kin, ancestors or divinities, the 'demon' metaphor of Awyu-Ndumut speakers is exceptionally negative, because it is a compliment to be assimilated to divinities or ancestral spirits in most other parts of New Guinea. The very negative contexts in which the 'demon' terms are used in Awyu-Ndumut languages — swear words, infanticide and putrid corpses - tell a different story.

Given the fact that for most Awyu-Ndumut speakers in the interior there is no economic alternative to their clan lands and given the strong emotional ties to the ancestral lands, it is to be expected that even with mitigation of the original force of the 'demon' nouns to denote foreigners, the foreigners will continue to be perceived as a threat to clan lands, land rights, survival and identity, with the concomitant ambivalence towards the 'demon-language', Indonesian.

It is important to reiterate that calling Indonesian 'demon-language' in itself is not an expression of specific anti-Indonesian political sentiments; all foreigners, irrespective of their nationality, are 'demons' and all foreigners speak Papuan Malay when interacting with Awyu-Ndumut speakers, and they have done so long before Indonesia took control over West Papua. There is, however, a political element in the 'demon' terminology, in another sense, because clans are also political units in Awyu-Ndumut worlds: every foreigner that enters a clan land, crosses a territorial border, and is a threat to the clan land inherited from the ancestors.

Papuan languages such as Awyu-Ndumut languages are vital and unendangered only when their habitat, dispersed and small scale clan societies with clan lands in the jungle, is intact. Interaction with kampungs and the Indonesian language is no threat to Awyu-Ndumut languages as long as clan based living is allowed to continue. Speakers will just add another language, Papuan Malay, to their repertoire as they always have in multilingual clan-based New Guinea. But everywhere in New Guinea, both in Indonesian Papua and in the independent state of Papua New Guinea, where clan based patterns of life broke down and people were integrated in wider political and social frameworks of nation-states, linguistic diversity decreased rapidly.

Let us now turn to the 'witch' term, the other major term applied to people outside the boundaries of social personhood. The Korowai term xaxua 'witch' and the Kombai term khakhwa-rumu 'witch-male' are used for male cannibalistic witches. The Kombai term makes the cultural norm explicit that witches are males, although both Korowai and Kombai acknowledge that occasionally women can be witches. 
In principle, every death of a yanop '(social) person' is caused by witchcraft. Since a very small child is not yet fully a 'social person' and very many of them die before their first birthday, their death often does not trigger witchcraft accusations.

The outside world, foreigners and anything they brought, from flashlights to the Indonesian language, were never talked about in 'witch' terms, always and only in 'demon' terms. Both 'demon' and 'witch' terms denote people outside the boundaries of social personhood but 'witches' are the enemy within, and restricted to males. Foreigners were never accused of being 'witches', fortunately so in my personal case.

\section{Conclusion}

Summarizing we can say that the politically fragmented, dispersed, small, loose-knit, open clan communities of Awyu-Ndumut speakers, with a strong tendency towards individual and clan autonomy, gave language a specific place in social life. This is reflected in the role of language in identity construction, in language names, in how language is talked about, in borrowing and multilingualism as a way to express one's identity as a cluster of relations, in the presence of mother's language/dialect and father's language/dialect in the socialization of children to reflect bilateral identity, and in linguistic ideologies as expressed in special speech registers.

The relation between Awyu-Ndumut languages and varieties of Indonesian can also be understood much better once that relation is viewed from the point of view of clan communities and the dynamics of clan land and kampung. Indonesian is the language of the kampung and its institutions and it is the bahasa umum, the lingua franca. Since Indonesian, in its local Papuan Malay variety, was already the lingua franca in New Guinea centuries before Indonesia took control, it is hardly associated with Indonesia as the controlling nation-state; rather, it is the language used by outsiders, 'demons', people outside the boundaries of social personhood, that have disgusting habits, skins and smells and who interfere with the lives of normal 'persons' and may even in the end claim clan lands. The Awyu-Ndumut languages, by contrast, are languages of 'humans', people within the boundaries of social personhood, and above all the languages of the clan lands, or to use the Korowai term bolü-aup 'clan land language'.

Vrije Universiteit, Amsterdam

Correspondence address: lj.de.vries@let.vu.nl 


\section{Note}

1. I was enabled to write this article because of a generous invitation to be a visiting scholar at the Cairns Institute of James Cook University, Cairns, Australia in 2010. Thanks are due to professors Dixon and Aikhenvald for the invitation and stimulating discussions. I extensively used Stasch's dissertation $(2001,2009)$ for the first part of the article and his article on Korowai ambivalent perceptions of Indonesian (Stasch 2007) for the second part. Many, many hours of conversations with Gert van Enk and Geyo Weremba on key concepts such as "demons", "witches" and "clan lands" have also found their way into this article.

\section{References}

Aikhenvald, Alexandra. 2008. Language contact along the Sepik River, Papua New Guinea. Anthropological Linguistics 50(1). 1-66.

Boelaars, Jan. 1970. Mandobo's tussen de Digoel en de Kao. Bijdragen tot een etnografie. [Mandobos between the Digul and Kao. Contributions to an ethnography]. Assen: Van Gorcum.

Drabbe, Peter. 1950. Twee dialecten van de Awju-taal. [Two dialects of the Awju language]. Bijdragen van het Koninklijk Instituut 106. 92-147.

Drabbe, P. 1957. Spraakkunst van het Aghu-dialect van de Awju-taal. [Grammar of the Aghu dialect of the Awju language]. Royal Institute of Linguistics and Anthropology (KITLV). The Hague: Nijhoff.

Drabbe, P. 1959. Kaeti en Wambon. Twee Awju-dialecten. [Kaeti and Wambon. Two Awju dialects]. The Hague: KITLV.

Enk, van Gerrit J. \& Lourens de Vries. 1997. The Korowai of Irian Jaya: their language in its cultural context. Oxford: Oxford University Press.

Foley, William A. 1997. Anthropological linguistics: an introduction. Oxford: Blackwell.

Foley, William A. 2005. Personhood and linguistic identity, purism and variation. Language Documentation and Description 3. 157-180.

Healy, Alan. 1970. Proto-Awyu-Dumut phonology. In Stephen A. Wurm \& Donald C. Laycock (eds.), Pacific linguistic studies in honour of Arthur Capell (Pacific Linguistics C-13), 9971061. Canberra: Australian National University.

Heeschen, Volkert. 1998. An ethnographic grammar of the Eipo language. Berlin: Dietrich Reimer.

Stasch, Rupert. 2001. Figures of alterity among Korowai of Irian Jaya: kinship, mourning and festivity in a dispersed society. Chicago: University of Chicago dissertation.

Stasch, Rupert. 2007. Demon language. The otherness of Indonesian in a Papuan community. In Miki Makihara \& Bambi B. Schieffelin (eds.), Consequences of contact: language ideology and sociocultural transformations in Pacific societies, 96-124. Oxford: Oxford University Press.

Stasch, Rupert. 2008. Referent-wrecking in Korowai: a New Guinea abuse register as ethnosemiotic protest. Language in Society 37(1). 1-25.

Stasch, Rupert. 2009. Society of others: kinship and mourning in a West Papuan place. Berkeley: University of California Press.

Susanto, Yunita. 2004. Report on the Mapi River survey. South coast of Irian Jaya. Indonesia. Dallas: SIL International. http://www.sil.org/silesr/abstract.asp?ref=2004-003 (accessed 23 May 2010).

Voorhoeve, Clemens L. 2001. Proto Awyu-Dumut phonology II. In A. Pawley, M. Ross and D. Tryon (eds.), The Boy from Bundaberg. Studies in Melanesian Linguistics in Honour of Tom Dutton. Canberra: Pacific Linguistics, 361-381. 


\section{L. de Vries}

Voorhoeve, Clemens L. 2005. Asmat-Kamoro, Awyu-Dumut and Ok: an enquiry into their linguistic relationships. In: Andrew Pawley, Robert Attenborough, Jack Golson and Robin Hide (eds.), Papuan Pasts. Cultural, linguistic and biological histories of Papuan-speaking peoples, 145167. Canberra: Pacific Linguistics.

Vries, Lourens de \& Robinia Wiersma. 1992. An outline of the morphology of Wambon of the Irian Jaya Upper-Digul area. Royal Institute of Linguistics and Anthropology. Leiden: KITLV.

Vries, Lourens de. 1993. Forms and functions in Kombai, an Awyu language of Irian Jaya. (Pacific Linguistics B-108). Canberra: Australian National University.

Vries, Lourens de. 1995. Demonstratives, referent identification and topicality in Wambon and some other Papuan languages. Journal of Pragmatics 24. 513-533.

Vries, Lourens de. 2005. Towards a typology of tail-head linkage in Papuan languages. Studies in Language 29(2). 363-384.

Vries, Lourens de. 2006. Areal pragmatics of New Guinea: thematization, distribution and recapitulative linkage in Papuan languages. Journal of Pragmatics 38. 811-828.

Vries, Lourens de. 2010. From clause conjoining to clause chaining in Dumut languages of New Guinea. Studies in Language 34(2). 327-349. 